\title{
C677T polymorphism increases the risk of early spontaneous abortion
}

\author{
Yongjie Liu $^{1}$ (D) $\cdot$ Fan Zhang ${ }^{1} \cdot$ Liang Dai $^{1}$ \\ Received: 14 February 2019 / Accepted: 29 May 2019 / Published online: 17 June 2019 \\ (C) The Author(s) 2019
}

\begin{abstract}
Purpose To investigate the relationship of the methylenetetrahydrofolate reductase (MTHFR) C677T polymorphism in male population having spouses with early spontaneous abortion.

Methods A total of 345 males whose spouses had at least one early spontaneous abortion were included in the study group, and 145 males who planned to have a second child were included in the control group. Semen was collected in a sterile cup by masturbation. After liquefaction, the sperm concentration and forward motility sperm rate (PR) were obtained. The genomic DNA was extracted from peripheral vein, followed by MTHFR C677T polymorphism detection through PCR-gold magnetic nanoparticle chromatography.

Results The numbers of alleles and genotypes of MTHFR in the case group were 303 (C), 387 (T), 64 (CC), 175 (CT), and 106 (TT) cases, respectively. The numbers of allele and genotype of MTHFR in the control group were 167 (C), 123 (T), 145 (CC), 65 (CT), and 29 (TT) cases. There were significant differences in the distribution frequency of genotypes $\left(\chi^{2}=17.005, P=0.000\right)$ and alleles $\left(\chi^{2}=15.295, P=0.000\right)$ between the two groups. For cases with more spontaneous abortion, more cases had CT and TT phenotypes. Participants with genotype CT had the highest sperm concentration and PR in both groups $(P<0.05)$.

Conclusions MTHFR could affect sperm DNA integrity through affecting DNA methylation, which led to an increase in the rate of early spontaneous abortion in spouses.
\end{abstract}

Keywords Male $\cdot$ MTHFR C677T polymorphism $\cdot$ Early spontaneous abortion

\section{Introduction}

Spontaneous abortion is one of the prevalent negative reproductive outcomes among women around the world, which is a great challenge faced by maternal health promotion [1]. Spontaneous abortion is defined as the loss of a clinically recognized pregnancy that occurs before 20 weeks of gestational age [2]. According to the time of pregnancy termination, spontaneous abortion can be classified as early abortion $(<12$ weeks) and late abortion $(\geq 12$ weeks) [3]. Multiple

Electronic supplementary material The online version of this article (https://doi.org/10.1007/s10815-019-01500-2) contains supplementary material, which is available to authorized users.

Yongjie Liu

lyj1722006@126.com

1 Department of Reproductive Center, Yinchuan Maternal and Child Health Hospital, No. 56, Culture West Street, Xingqing District, Yinchuan 750001, Ningxia, China pathological factors are related to early spontaneous abortion, such as abnormal embryo chromosomes, abnormal reproductive organs of pregnant women, and infection of reproductive tract [4]. However, there are limited male reproductive examinations for early spontaneous abortion analysis.

Methylenetetrahydrofolate reductase (MTHFR) is a key enzyme of folate/homocysteine pathway [5]. MTHFR play a critical role in the process of reproduction. The adverse effects of MTHFR deficiency on spermatogenesis maybe mediated partly by alterations in the transmethylation pathway, suggesting that betaine supplementation may provide a way to bypass MTHFR deficiency and its adverse effects on spermatogenesis by maintaining normal methylation levels within male germ cells [6]. It has been reported that MTHFR gene polymorphism can affect sperm quality [7]. Homozygosity for MTHFR C677T (late and early-late) and A1298C (earlylate) was the risk factor for idiopathic recurrent pregnancy losses and was not related to total homocysteine levels [8].

In this study, the MTHFR gene C677T polymorphism of males whose spouses had been through early spontaneous abortion was detected, the relationship between MTHFR 
C677T polymorphism and early spontaneous abortion was analyzed, and the aim was to find possible measures to intervene early spontaneous abortion from male perspective.

\section{Materials and methods}

\section{Study subjects}

A total of 345 males whose spouses had at least one early spontaneous abortion were included in the case group, and 145 males planned to have a second child were included in the control group. All subjects in the case group visited the reproductive center of our hospital from January 2015 to August 2017. All subjects were asked about their medical history and underwent the physical examination of genital system. Patients with diseases such as chromosomal abnormality, cryptorchidism, varicocele, and reproductive system infection were excluded. The age of subjects was in the range of 21 to 42 years $(30.29 \pm 4.85)$. This study was approved by the Ethics Committee of our hospital. Before study, informed consent was obtained from each subject.

\section{Semen analysis}

Semen was collected through masturbation after 3-5 days of abstinence, followed by liquidation at $36{ }^{\circ} \mathrm{C}$. Sperm concentration and forward motility sperm rate (PR) were obtained by using a computer-assisted sperm analysis system (Beijing, Tsinghua Tongfang MX7.8.5-T) according to the WHO laboratory test manual for human semen (5th edition) [9].

\section{MTHFR C677T detection}

The C677T mutation was analyzed by PCR-gold magnetic nanoparticle chromatography (Xi'an GoldMag Nanobiotech Co., Ltd.) with Applied Biosystems 2720 Thermal Cycler.

\section{Statistical analysis}

Data were statistically evaluated using SPSS statistics v.17.0. The distribution of the allele of the MTHFR gene C677T between the two groups was compared. The difference of sperm concentration and PR of subjects in the two groups was analyzed. $F$ test was used for the measurement data of multiple groups, $t$ test was used for the comparison of the two groups, and chi-square test was used for comparing counting data. Continuous data were presented as the mean \pm SD. $P<0.05$ was considered to be statistically significant.

\section{Results}

\section{Basic information of subjects}

In the case group, the age of 345 males ranged (mean \pm SD) from 21 to $42(30.19 \pm 4.46)$ years old, and the average BMI was $24.39 \pm 3.84 \mathrm{~kg} / \mathrm{m}^{2}$. A total of 106 cases had 1 time of spontaneous abortion, 125 cases had 2 times, and 114 cases had more than 2 times of spontaneous abortion. In the control group, the age of 145 males ranged (mean \pm SD) from 23 to 40 $(30.89 \pm 5.39)$ years old, and the average BMI was $24.27 \pm$ $3.73 \mathrm{~kg} / \mathrm{m}^{2}$.

\section{Distribution of genotypes and alleles of MTHFR C677T}

The genotyping results were shown in Table 1 . In the case group, 64 cases had the genotype of CC, 175 cases had the genotype of CT, and 106 cases had the genotype of TT. In the control group, 51 cases had the genotype of CC, 65 cases had the genotype of CT, and 29 cases had the genotype of TT. Significant less proportion of cases had CC genotype $\left(\chi^{2}=\right.$ $17.005, P<0.001)$. In patients with 2 spontaneous abortion, 32 cases $(25.6 \%)$ had CC, 62 cases $(49.6 \%)$ had CT, and 31 cases $(24.8 \%)$ had TT, respectively (Supplemental Table 1). In patients with more than 2 spontaneous abortion, 15 cases (13.2\%) had CC, 52 (45.6\%) cases had CT, and 47 cases $(41.2 \%)$ had TT, respectively. In patients with more spontaneous abortion, more cases had CT and TT. The analysis of allele distribution showed that there were 303 cases with $\mathrm{C}$ and 387 cases with $\mathrm{T}$ in the case group, while in the control group, allele $C$ was found in 167 cases, and $T$ was found in 123 cases. Significant less allele $\mathrm{C}$ was observed in the case group $\left(\chi^{2}=\right.$ 15.295, $P<0.001)$.

\section{Sperm concentration and PR between the two groups}

In the case group, the sperm concentrations were $(74.42 \pm$ $55.46) \times 10^{6} / \mathrm{ml}$ for $\mathrm{CC},(52.76 \pm 32.38) \times 10^{6} / \mathrm{ml}$ for $\mathrm{CT}$, and $(96.48 \pm 58.85) \times 10^{6} / \mathrm{ml}$ for TT. The average sperm concentration was $(78.79 \pm 59.66) \times 10^{6} / \mathrm{ml}$. In the control group, the sperm concentrations were $(42.58 \pm 27.42) \times 10^{6} / \mathrm{ml}$ for $\mathrm{CC},(65.60 \pm 30.77) \times 10^{6} / \mathrm{ml}$ for CT, and $(41.85 \pm 34.49) \times$ $10^{6} / \mathrm{ml}$ for TT. The average sperm concentration was $(52.76$ $\pm 32.38) \times 10^{6} / \mathrm{ml}$. The sperm concentration in the case group was significantly higher than that in the control group. In both groups, subjects with the genotype of CT showed the highest concentration of sperm, while those with the genotype of TT had the lowest sperm concentration (Table 2).

The sperm PR was $43.56 \pm 18.58 \%$ in the case group and $37.84 \pm 15.68 \%$ in the control group $(P<0.05)$. In the case group, the sperm PR were $39.15 \pm 19.51 \%$ for $\mathrm{CC}, 48.12 \pm$ $16.26 \%$ for CT, and $38.69 \pm 19.86 \%$ for TT, respectively. The average sperm PR was $43.56 \pm 18.58 \%$. In the control group, 
Table 1 Distribution of genotypes and alleles of MTHFR gene C677T

\begin{tabular}{llllll}
\hline Genotype/allele & & Case group & Control group & OR (95\% CI) & $\chi^{2}$ \\
\hline Genotype & CC & $64(18.55)$ & $51(35.17)$ & 1 & 17.005 \\
& CT & $175(50.7)$ & $65(44.83)$ & $1.637(1.223-2.192)$ & $<0.001$ \\
& TT & $106(30.73)$ & $29(20)$ & $2.064(1.409-3.025)$ & $<0.001$ \\
Total & & $345(100)$ & $145(100)$ & & 15.295 \\
Allele & $\mathrm{C}$ & $303(43.91)$ & $167(57.59)$ & $1.473(1.211-1.793)$ & \\
& $\mathrm{T}$ & $387(56.09)$ & $123(42.41)$ & & \\
Total & $690(100)$ & $290(100)$ & & \\
\hline
\end{tabular}

the sperm PR were $30.66 \pm 16.07 \%$ for CC, $44.31 \pm 15.58 \%$ for CT, and $35.97 \pm 7.38 \%$ for TT. The average sperm PR was $37.84 \pm 15.68 \%$. The sperm PR in the case group was significantly higher than in the control group. In both groups, subjects with the genotype of CT showed the highest sperm PR (Table 3).

\section{Discussion}

MTHFR gene encodes one of the key enzymes in folate metabolism and is located on chromosome 1 (1p36.3), which has 12 exons [10]. By taking part in methionine cycle, MTHFR can affect gene expression through DNA methylation. Dozens of mutations of MTHFR gene have been found so far, and more and more diseases related to new mutations continue to be discovered [11]. It has been reported that C677T polymorphism of MTHFR gene is closely related to atherosclerosis, hypertension, heart disease, birth defects, Alzheimer's disease, and hormone metabolism [12], which have drawn great attention. Exogenous folic acid supplementation can reduce the risk of these diseases.
The 677th nucleotide mutation is the most common SNP for MTHFR, which provides three kinds of genotype of MTHFR namely CC (wild type), CT (mixed type), and TT (homozygous) [13]. In vitro experiments showed the decrease of heat resistance and activity of mutant MTHFR enzyme, which resulted in maternal toxicity and the abortion by affecting Hcy metabolism [14]. In fact, males and females have equal contribution for early spontaneous abortion. Cornet et al. showed that defective methylation linked to MTHFR might contribute to sperm pathogenesis via increased sperm nucleus decondensation index [15]. In this study, males whose spouses had at least one early spontaneous abortion and males planned to have a second child were included as study subjects. The results of MTHFR C677T genotyping showed that the proportion of subjects with the genotype of TT in the case group was significantly higher than in the control group, which was consistent with the report about the percentage of TT genotype for local men (17.8\%, 32/180) [16] and women $(21.44 \%, 131 / 611)$ [17]. Such high percentage of TT genotype in the case group deserves a great attention. MTHFR is involved in DNA methylation, which is one of the most important regulatory mechanisms during the formation of spermatozoa. The decrease of MTHFR activity can lead to the
Table 2 Sperm concentration of different genotypes between the two groups

\begin{tabular}{llrllll}
\hline & & $n$ & $\begin{array}{l}\text { Sperm concentration } \\
\left(\times 10^{6} / \mathrm{ml}\right)\end{array}$ & $F / t$ & $P$ & $95 \%$ CI \\
\hline Case group & CC & 64 & $74.42 \pm 55.46$ & 20.442 & $<0.001$ & $60.56-88.27$ \\
& CT & 175 & $96.48 \pm 58.85^{\mathrm{a}}$ & & & $87.70-105.26$ \\
& TT & 106 & $52.23 \pm 53.22^{\mathrm{a}, \mathrm{b}}$ & & & $41.98-62.48$ \\
Control group & CC & 51 & $42.58 \pm 27.42^{\mathrm{a}, \mathrm{b}}$ & 10.506 & $<0.001$ & $34.87-50.29$ \\
& CT & 65 & $65.60 \pm 30.77^{\mathrm{b}, \mathrm{d}}$ & & & $57.98-73.23$ \\
\multirow{5}{*}{ Total } & TT & 29 & $41.85 \pm 34.49^{\mathrm{a}, \mathrm{b}, \mathrm{e}}$ & & & $28.73-54.97$ \\
& Case group & 345 & $78.79 \pm 59.66$ & 4.960 & $<0.001$ & $72.47-85.11$ \\
& Control group & 145 & $52.76 \pm 32.38$ & & & $47.44-58.07$ \\
\hline
\end{tabular}

${ }^{\text {a }}$ Compared with the case group CC, $P<0.05$

${ }^{\mathrm{b}}$ Compared with the case group CT, $P<0.05$

${ }^{\mathrm{c}}$ Compared with the case group TT, $P<0.05$

${ }^{\mathrm{d}}$ Compared with the control group CC, $P<0.05$

${ }^{\mathrm{e}}$ Compared with the control group CT, $P<0.05$ 
Table 3 Sperm PR of different genotypes between the two groups

\begin{tabular}{llrllll}
\hline & & $\mathrm{n}$ & Sperm PR (\%) & $F / t$ & $P$ & $95 \%$ CI \\
\hline Case group & CC & 64 & $39.15 \pm 19.51$ & 11.356 & $<0.001$ & $34.28-44.03$ \\
& CT & 175 & $48.12 \pm 16.26^{\mathrm{a}}$ & & & $45.70-50.55$ \\
& TT & 106 & $38.69 \pm 19.86^{\mathrm{b}}$ & & & $34.87-42.52$ \\
Control group & CC & 51 & $30.66 \pm 16.07^{\mathrm{a}, \mathrm{b}, \mathrm{c}}$ & 12.919 & $<0.001$ & $26.14-35.18$ \\
& CT & 65 & $44.31 \pm 15.58^{\mathrm{c}, \mathrm{d}}$ & & & $40.45-48.17$ \\
& TT & 29 & $35.97 \pm 7.38 \mathrm{~b}^{\mathrm{e}}$ & & & $33.16-38.77$ \\
Total & Case group & 345 & $43.56 \pm 18.58$ & 2.908 & 0.004 & $41.60-45.53$ \\
& Control group & 145 & $37.84 \pm 15.68$ & & & $35.27-40.42$ \\
\hline
\end{tabular}

${ }^{\text {a }}$ Compared with the case group CC, $P<0.05$

${ }^{\mathrm{b}}$ Compared with the case group CT, $P<0.05$

${ }^{\mathrm{c}}$ Compared with the case group TT, $P<0.05$

${ }^{\mathrm{d}}$ Compared with the control group $\mathrm{CC}, P<0.05$

${ }^{\mathrm{e}}$ Compared with the control group $\mathrm{CT}, P<0.05$ fragmentation rate of DNA and increased rate of spontaneous abortions [18]. Aarabi et al. found that folic acid supplementation in MTHFR 677TT genotype mice resulted in no changes in general health, sperm counts, or methylation of imprinted genes, suggesting folic acid might be of little help in these patients [19]. The effect of betaine supplement according to the genotyping of MTHFR on sperm DNA integrity and spontaneous abortion of spouse will be investigated in the future.

In present study, sperm concentration and PR were assessed in two groups. It was found that the sperm concentration and PR in the case group were significantly higher than those in the control group. The CT genotype in the case group was the highest. The results were consistent with the report of Ghorbian et al. [20], and they found that the sperm concentrations of the case group and the control group were (45.57 \pm $57.67) \times 10^{6} / \mathrm{ml}$ and $(37.97 \pm 25.93) \times 10^{6} / \mathrm{ml}$. But Wang et al [21] had given different results; the sperm concentration and PR in the case group and the control group were (75.23 \pm $48.08) \times 10^{6} / \mathrm{ml}$ and $33.19 \pm 16.40 \%$ and $(93.03 \pm 59.62) \times$ $10^{6} / \mathrm{ml}$ and $50.79 \pm 17.64 \%$, respectively. The results from Absalan et al. [22] indicated no significant differences in sperm concentration and PR between the case group and the control group. However, all reports indicated that sperm concentration and PR in the case group and the control group were significantly higher than the normal standard. The sperm concentration and PR of males with early spontaneous abortion cannot be used in the evaluation, treatment, and prevention of early spontaneous abortion [23]; thus, DNA detection was necessary. Carlus et al. demonstrated that MTHFR C677T polymorphism might raise plasma Hcy level [24]; Hcy can cause an increase of oxygen free radicals and affect sperm quality, or cause arteriosclerosis and affect reproductive function. In this study, subjects with CT genotype had the highest percentage in both group, suggesting that MTHFR-mediated
Hcy metabolism had a limited effect on the reproductive system, and it worked in a different way to the reproductive system compared with other systems. It may have a little effect on spermatogenesis maturity.

In our study, we observed that cases with more spontaneous abortion had a higher proportion of CT and TT. The compound heterozygotes $677 \mathrm{CT}$ and $1298 \mathrm{AC}$ have elevated homocysteine [25]; thus, this population might be at a higher risk of abortion. These two SNPs were not tested in our study and that was one limitation of our work.

\section{Conclusion}

In summary, the MTHFR C677T polymorphism had a little effect on sperm concentration and PR. However, C677T polymorphism could affect the integrity of sperm DNA by affecting the DNA methylation, which led to an increase in the rate of early spontaneous abortion. The C677T polymorphism of MTHFR gene should be screened before pre-pregnancy. Due to the small sample size, further study with large sample will be performed to verify the results of this study.

Funding source This study was supported by the Ningxia Natural Science Foundation Funded Project (17242).

\section{Compliance with ethical standards}

This study was approved by the Ethics Committee of our hospital.

Open Access This article is distributed under the terms of the Creative Commons Attribution 4.0 International License (http:// creativecommons.org/licenses/by/4.0/), which permits unrestricted use, distribution, and reproduction in any medium, provided you give appropriate credit to the original author(s) and the source, provide a link to the Creative Commons license, and indicate if changes were made. 


\section{References}

1. Zheng D, Li C, Wu T, Tang K. Factors associated with spontaneous abortion: a cross-sectional study of Chinese populations. Reprod Health. 2017;14(1):33.

2. Ramandeep K, Kapil G, Harkiran K. Correlation of enhanced oxidative stress with altered thyroid profile: probable role in spontaneous abortion. Int J Appl Basic Med Res. 2017;7(1):20-5.

3. Zhou L, Gao X, Wu Y, Zhang Z. Analysis of pregnancy outcomes for survivors of the vanishing twin syndrome after in vitro fertilization and embryo transfer. Eur J Obstet Gynecol Reprod Biology. 2016;203:35-9.

4. Wu T, Yin B, Zhu Y, Li G, Ye L, Chen C, et al. Molecular cytogenetic analysis of early spontaneous abortions conceived from varying assisted reproductive technology procedures. Mol Cytogenet 2016;9:79.

5. Rai V. Methylenetetrahydrofolate reductase (MTHFR) C677T polymorphism and Alzheimer disease risk: a meta-analysis. Mol Neurobiol. 2017;54(2):1173-86.

6. TL K, et al. Infertility in 5,10-methylenetetrahydrofolate reductase (MTHFR)-deficient male mice is partially alleviated by lifetime dietary betaine supplementation. Biol Reprod. 2005;72(3):667.

7. Wu W, Shen O, Qin Y, Lu J, Niu X, Zhou Z, et al. Methylenetetrahydrofolate reductase C677T polymorphism and the risk of male infertility: a meta-analysis. Int J Androl. 2012;35(1):18-24.

8. Mtiraoui N, Zammiti W, Ghazouani L, Braham NJ, Saidi S, Finan RR, et al. Methylenetetrahydrofolate reductase C677T and A1298C polymorphism and changes in homocysteine concentrations in women with idiopathic recurrent pregnancy losses. Reproduction. 2006;131(2):395-401.

9. Organisation WH. WHO laboratory manual for the examination and processing of human semen. 5th ed. Geneva: World Health Organisation; 2010. p. 10-26.

10. Karimian M, Colagar AH. Association of C677T transition of the human methylenetetrahydrofolate reductase (MTHFR) gene with male infertility. Reprod Fertil Dev. 2016;28(6):785.

11. Forges T, Chery C, Audonnet S, Feillet F, Gueant JL. Lifethreatening methylenetetrahydrofolate reductase (MTHFR) deficiency with extremely early onset: characterization of two novel mutations in compound heterozygous patients. Molecular Genetics \& Metabolism. 2010;100(2):143-8.

12. Stoccoro A, Tannorella P, Salluzzo MG, Ferri R, Romano C, Nacmias B, et al. The Methylenetetrahydrofolate Reductase C677T Polymorphism and Risk for Late-Onset Alzheimer's disease: Further Evidence in an Italian Multicenter Study. J Alzheimers Dis 2017;56:1451.
13. Gutiérrezálvarez O, et al. Involvement of MTHFR and TPMT genes in susceptibility to childhood acute lymphoblastic leukemia (ALL) in Mexicans. Drug Metabol Drug Interact. 2016;31(1):41-6.

14. Obwegeser R, Hohlagschwandtner M, Sinzinger H. Homocysteine-a pathophysiological cornerstone in obstetrical and gynaecological disorders? Hum Reprod Update. 1999;5(1): 64-72.

15. Cornet D, Cohen M, Clement A, Amar E, Fournols L, Clement P, et al. Association between the MTHFR-C677T isoform and structure of sperm DNA. J Assist Reprod Genet. 2017;34(10):1283-8.

16. Qiu XF, et al.. Association between methylenetetrahydrofolate reductase gene C677T polymorphism and male infertility with azoospermia or severe oligozoospermia and asthenospermia in Ningxia Han population. Journal of Ningxia Medical University. 2011.

17. Yang Y, Tang J, Yanqiang LU. Analysis on single nucleotide polymorphisms of MTHFR and MTRR genes among Hui and Han women in Yinchuan city. Maternal \& Child Health Care of China. 2015.

18. Carol, et al. Sperm DNA fragmentation, recurrent implantation failure and recurrent miscarriage. Asian J Androl. 2015;17(4):681-5.

19. Aarabi M, Christensen KE, Chan D, Leclerc D, Landry M, Ly L, et al. Testicular MTHFR deficiency may explain sperm DNA hypomethylation associated with high dose folic acid supplementation. Hum Mol Genet. 2018;27(7):1123-35.

20. Ghorbian S, Saliminejad K, Sadeghi MR, Javadi GR, Kamali K, Amirjannati N, et al. The association between $\mathrm{Y}$ chromosome microdeletion and recurrent pregnancy loss. Iran Red Crescent Med J. 2012;14(6):358-62.

21. Wang R, et al. The impact of semen quality, occupational exposure to environmental factors and lifestyle on recurrent pregnancy loss. J Assist Reprod Genet. 2013;30(11):1513-8.

22. Absalan F, Ghannadi A, Kazerooni M, Parifar R, Jamalzadeh F, Amiri S. Value of sperm chromatin dispersion test in couples with unexplained recurrent abortion. J Assist Reprod Genet. 2012;29(1): $11-4$.

23. Yang Y, et al. Association between C677T and A1298C polymorphisms of the MTHFR gene and risk of male infertility: a metaanalysis. Genet Mol Res Gmr. 2016;15(2).

24. Carlus SJ, et al. The MTHFR C677T polymorphism is associated with mitral valve rheumatic heart disease. Eur Rev Med Pharmacol Sci. 2016;20(1):109.

25. Castro R, Rivera I, Ravasco P, Jakobs C, Blom HJ, Camilo ME, et al. 5, 10-Methylenetetrahydrofolate reductase $677 \mathrm{C} \rightarrow \mathrm{T}$ and $1298 \mathrm{~A} \rightarrow \mathrm{C}$ mutations are genetic determinants of elevated homocysteine. J Qjm. 2003;96(4):297-303.

Publisher's note Springer Nature remains neutral with regard to jurisdictional claims in published maps and institutional affiliations. 